\title{
Comprehensive genomic sequencing detects important genetic differences between right-sided and left-sided colorectal cancer
}

\author{
Yoshifumi Shimada ${ }^{1}$, Hitoshi Kameyama ${ }^{1}$, Masayuki Nagahashi ${ }^{1}$, Hiroshi Ichikawa ${ }^{1}$, \\ Yusuke Muneoka ${ }^{1}$, Ryoma Yagii,2, Yosuke Tajima ${ }^{1}$, Takuma Okamura ${ }^{1}$, Masato \\ Nakano' ${ }^{1}$, Jun Sakata ${ }^{1}$, Takashi Kobayashi' ${ }^{1}$, Hitoshi Nogami ${ }^{2}$, Satoshi Maruyama ${ }^{2}$, \\ Yasumasa Takii ${ }^{2}$, Tetsu Hayashida ${ }^{3}$, Hiromasa Takaishi ${ }^{4}$, Yuko Kitagawa ${ }^{3}$, Eiji \\ Oki $^{5}$, Tsuyoshi Konishi' ${ }^{6}$, Fumio Ishida7, Shin-ei Kudo ${ }^{7}$, Jennifer E. Ring ${ }^{8}$, Alexei \\ Protopopov $^{8}$, Stephen Lyle ${ }^{8,9}$, Yiwei Ling ${ }^{10}$, Shujiro Okuda ${ }^{10}$, Takashi Ishikawa ${ }^{1,11}$, \\ Kohei Akazawa ${ }^{11}$, Kazuaki Takabe ${ }^{12,13}$ and Toshifumi Wakai ${ }^{1}$ \\ ${ }^{1}$ Division of Digestive and General Surgery, Niigata University Graduate School of Medical and Dental Sciences, Niigata, \\ Japan \\ ${ }^{2}$ Department of Surgery, Niigata Cancer Center Hospital, Niigata, Japan \\ ${ }^{3}$ Department of Surgery, Keio University School of Medicine, Tokyo, Japan \\ ${ }^{4}$ Department of Internal Medicine, Keio University School of Medicine, Tokyo, Japan \\ ${ }^{5}$ Department of Surgery and Science, Graduate School of Medical Sciences, Kyushu University, Fukuoka, Japan \\ ${ }^{6}$ Department of Gastroenterological Surgery, Gastroenterological Center, Cancer Institute Hospital, Japanese Foundation for \\ Cancer Research, Tokyo, Japan \\ ${ }^{7}$ Digestive Disease Center, Showa University Northern Yokohama Hospital, Yokohama, Japan \\ ${ }^{8} \mathrm{KEW}$, Inc., Cambridge, MA, USA \\ ${ }^{9}$ University of Massachusetts Medical School, Worcester, MA, USA \\ ${ }^{10}$ Division of Bioinformatics, Niigata University Graduate School of Medical and Dental Sciences, Niigata, Japan \\ ${ }^{11}$ Department of Medical Informatics, Niigata University Graduate School of Medical and Dental Sciences, Niigata, Japan \\ ${ }^{12}$ Breast Surgery, Roswell Park Cancer Institute, Buffalo, NY, USA \\ ${ }^{13}$ Department of Surgery, University at Buffalo Jacobs School of Medicine and Biomedical Sciences, The State University of \\ New York, Buffalo, NY, USA \\ Correspondence to: Toshifumi Wakai, email: wakait@med.niigata-u.ac.jp \\ Kazuaki Takabe, email: Kazuaki.Takabe@RoswellPark.org \\ Yoshifumi Shimada, email: shimaday@med.niigata-u.ac.jp
}

Keywords: colorectal cancer, right-sided, anti-EGFR therapy, next-generation sequencing, comprehensive genomic sequencing Received: April 08, $2017 \quad$ Accepted: August 08, $2017 \quad$ Published: August 24, 2017

Copyright: Shimada et al. This is an open-access article distributed under the terms of the Creative Commons Attribution License 3.0 (CC BY 3.0), which permits unrestricted use, distribution, and reproduction in any medium, provided the original author and source are credited.

\section{ABSTRACT}

Objectives: Anti-epidermal growth factor receptor (EGFR) therapy has been found to be more effective against left-sided colorectal cancer (LCRC) than rightsided colorectal cancer (RCRC). We hypothesized that RCRC is more likely to harbor genetic alterations associated with resistance to anti-EGFR therapy and tested this using comprehensive genomic sequencing.

Materials and methods: A total of $\mathbf{2 0 1}$ patients with either primary RCRC or LCRC were analyzed. We investigated tumors for genetic alterations using a 415-gene panel, which included alterations associated with resistance to anti-EGFR therapy: TK receptors (ERBB2, MET, EGFR, FGFR1, and PDGFRA), RAS pathway (KRAS, NRAS, HRAS, BRAF, and MAPK2K1), and PI3K pathway (PTEN and PIK3CA). Patients whose tumors had no alterations in these $\mathbf{1 2}$ genes, theoretically considered to respond to 


\begin{abstract}
anti-EGFR therapy, were defined as "all wild-type", while remaining patients were defined as "mutant-type".

Results: Fifty-six patients (28\%) and 145 patients (72\%) had RCRC and LCRC, respectively. Regarding genetic alterations associated with anti-EGFR therapy, only 6 of 56 patients (11\%) with RCRC were "all wild-type" compared with 41 of 145 patients $(28 \%)$ with LCRC $(P=0.009)$. Among the 49 patients who received anti-EGFR therapy, RCRC showed significantly worse progression-free survival (PFS) than LCRC $(P=0.022)$, and "mutant-type" RCRC showed significantly worse PFS compared with "all wild-type" LCRC $(P=0.004)$.

Conclusions: RCRC is more likely to harbor genetic alterations associated with resistance to anti-EGFR therapy compared with LCRC. Furthermore, our data shows primary tumor sidedness is a surrogate for the non-random distribution of genetic alterations in CRC.
\end{abstract}

\section{INTRODUCTION}

The colon is an embryological derivative of the midgut and hindgut separately, and thus the right-sided colon, the leftsided colon, and the rectum each have different anatomical and physiological features. Evidence shows that tumors arising from right colon have distinct clinical and biological characteristics compared with tumors of the left colon or rectum [1-6]. Right-sided colorectal cancer (RCRC) is generally characterized by being more common in women, and associated with Lynch syndrome, the serrated pathway, Mitogen-activated protein kinase signaling, microsatellite instability-high (MSI-H), deficiency of mismatch repair genes, CpG island methylation, and KRAS and BRAF mutations [710]. Left-sided colorectal cancer (LCRC) is more common in men, and associated with familial adenomatous polyposis syndrome, Wnt and EGFR signaling, chromosomal instability, $E R B B 1$ and $E R B B 2$ amplifications, and $A P C, p 53$, and $N R A S$ mutations $[10,11]$. Based on these molecular differences, sidedness of CRC is thought to be associated with efficacy of chemotherapy and targeted therapy.

The monoclonal antibodies cetuximab and panitumumab are epidermal growth factor receptor (EGFR) inhibitors that block downstream signaling of the EGFR pathway. Randomized phase III clinical trials have shown a survival benefit of these anti-EGFR monoclonal antibodies in $R A S$ wild-type metastatic CRC [12-14]; however, tumor location has not traditionally been included as a stratification criterion in clinical trials. Recently, several retrospective, unplanned analyses examined primary tumor sidedness and revealed that antiEGFR therapy clearly benefitted patients with LCRC, whereas patients with RCRC derived limited benefit [1517]. Consequently, while these analyses were limited by low numbers of RCRC patients, the related imbalance between groups, and no randomization; primary tumor sidedness of CRC has emerged as new predictive marker for efficacy of anti-EGFR therapy.

The mechanism of resistance to anti-EGFR therapy in patients with RCRC has not been fully elucidated. Although $R A S$ mutations are established biomarkers of efficacy to anti-EGFR therapy, anti-EGFR therapy is not effective for all patients with a $R A S$ wild-type tumor [1821]. Genetic alterations in tyrosine kinase (TK) receptors, the RAS pathway (other than KRAS and NRAS mutations), and the PI3K pathway are other possible mechanisms of resistance to anti-EGFR therapy $[22,23]$. While the most clinically important alterations, such as KRAS, NRAS, and $B R A F$ mutations, have been widely analyzed among patients with metastatic CRC, the other alterations have not been widely studied.

Next-generation sequencing projects, such as The Cancer Genome Atlas, have profiled genomic changes in many cancers including CRC [24]. We have similarly reported a genomic analysis of Japanese CRC patients using comprehensive genomic sequencing (CGS) $[25,26]$. CGS detects gene mutations and copy number alterations in TK receptors, and the RAS and PI3K pathway in a single assay. In the present analysis, we hypothesized that RCRC more frequently harbors genetic alterations associated with resistance to anti-EGFR therapy compared with LCRC. To test this hypothesis, we investigated these genetic alterations using CGS.

\section{RESULTS}

\section{Association between primary tumor sidedness and clinicopathological characteristics}

Fifty-six patients (28\%) and 145 patients (72\%) had RCRC and LCRC, respectively (Figure 1). Histopathological grade 3 was significantly associated with $\mathrm{RCRC}(P<0.001$; Table 1). Medullary type, mucinous type, and MLH1/MSH2 status were significantly associated with RCRC $(P=0.022$, $P=0.007$, and $P=0.024$, respectively; Table 2 ).

\section{Association between primary tumor sidedness} and genetic alterations evaluated using CGS

CGS of the 415-gene panel in our cohort of 201 patients detected genetic alterations in 268 genes (Supplementary Table 1). Mutations in KRAS, PIK3CA, 
RNF43, BRAF, ACVR2A, MSH6, and PALB2 were significantly associated with RCRC $(P=0.047, P=0.014$, $P=0.039, P<0.001, P=0.003, P=0.016$, and $P=0.001$, respectively; Figure 2), and mutations in $A P C, T P 53$ and $P T C H 1$ were significantly associated with LCRC $(P=$ $0.010, P=0.005$, and $P=0.036$, respectively; Figure 2 ).

The hypermutated tumor was significantly associated with RCRC $(P=0.008$; Table 2). Genetic alterations found in the 12 genes associated with resistance to anti-EGFR therapy (TK receptors: $E R B B 2, M E T, E G F R, F G F R 1$, and PDGFRA; RAS pathway: KRAS, NRAS, HRAS, BRAF, and $M A P K 2 K 1$; and PI3K pathway: PTEN and $P I K 3 C A$ ) are detailed in Supplementary Table 2. Of the 201 patients, 154 harbored one or more genetic alterations in these 12 genes with $80,63,8,2$, and 1 patients had $1,2,3,4$, and 5 gene alterations, respectively. Of the 56 RCRC patients, $6(11 \%)$ were wild-type in all 12 genes (termed "all wildtype"); while 41 of 145 patients $(28 \%)$ of LCRC were "all wild-type" ( $P=0.009$; Figure 3 , Table 3$)$.

\section{Efficacy of anti-EGFR therapy according to primary tumor sidedness and genetic alterations associated with resistance to anti-EGFR therapy}

Among the 49 patients treated with anti-EGFR therapy in addition to cytotoxic chemotherapy, patients with RCRC showed significantly worse progression- free survival (PFS) than patients with LCRC $(P=0.022$; Figure 4A). Regarding the 12 genes associated with antiEGFR therapy resistance in these 49 patients, 18, 25, and 6 patients had 0,1 and 2 genetic alterations, respectively. No significant difference was observed in PFS between "all wild-type" and "mutant-type" (Figure 4B), but the six patients with two genetic alterations showed significantly worse PFS than patients with no genetic mutations $(P=$ 0.005; Figure 4C). After stratification by primary tumor sidedness, we found $B R A F$ mutations were significantly associated with RCRC $(P=0.047$; Table 4$)$. When the 49 patients were classified into four groups according to primary tumor sidedness and genetic alterations associated with anti-EGFR therapy resistance, "mutant-type" RCRC showed a significantly worse PFS compared with "all wild-type" LCRC ( $P=0.004$; Figure 4D).

\section{DISCUSSION}

CGS analysis of genetic alterations in 201 primary CRCs revealed important genetic differences in relation to tumor sidedness: that there are genetic alterations in RCRC that are distinct from LCRC, and that CRCs wild-type in TK receptors and the RAS and PI3K pathways (termed "all wild-type" tumors and theoretically more likely to respond to anti-EGFR therapy), were significantly less common amongst RCRC. These genetic differences likely

\section{Location of primary tumor $(\mathrm{N}=201)$}

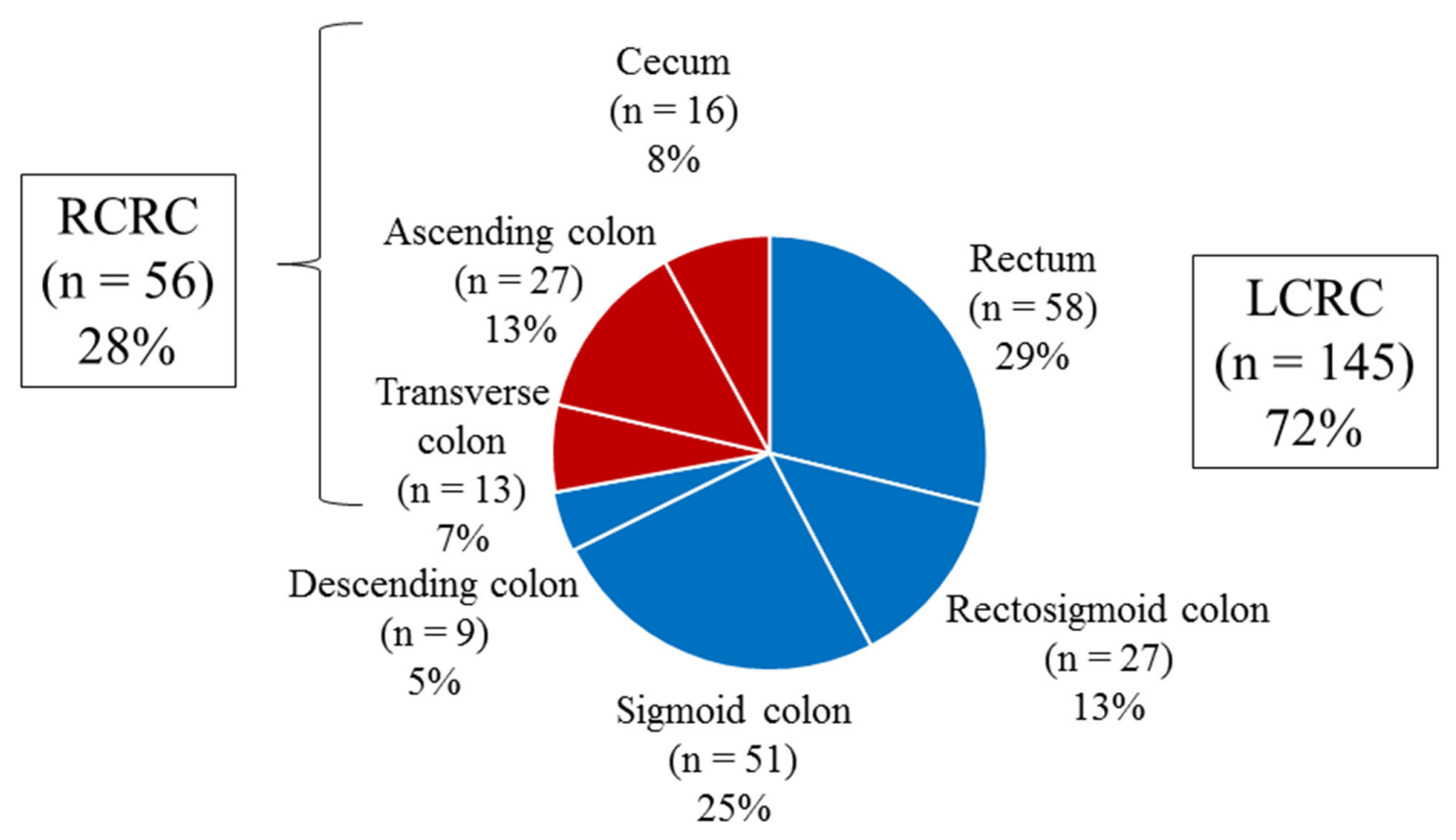

Figure 1: Primary tumor locations in right-sided colorectal cancer and left-sided colorectal cancer. RCRC, right-sided colorectal cancer; LCRC, left-sided colorectal cancer. 
Table 1: Association between primary tumor sidedness and clinicopathological characteristics $(\mathrm{N}=201)$

\begin{tabular}{|c|c|c|c|}
\hline \multirow[b]{2}{*}{ Variable } & \multicolumn{2}{|c|}{ Primary tumor sidedness } & \multirow{2}{*}{$P$-value } \\
\hline & Right $(n=56)$ & Left $(n=145)$ & \\
\hline \multicolumn{4}{|l|}{ Age (years) } \\
\hline$<65$ & 22 & 78 & 0.065 \\
\hline$\geq 65$ & 34 & 67 & \\
\hline \multicolumn{4}{|l|}{ Sex } \\
\hline Male & 29 & 55 & 0.074 \\
\hline Female & 27 & 90 & \\
\hline \multicolumn{4}{|c|}{ Tumor size (mm) } \\
\hline$<50$ & 23 & 65 & 0.630 \\
\hline$\geq 50$ & 33 & 80 & \\
\hline \multicolumn{4}{|l|}{$\mathrm{T}$ category } \\
\hline $\mathrm{T} 1,2$ & 6 & 18 & 0.739 \\
\hline $\mathrm{T} 3,4$ & 50 & 127 & \\
\hline \multicolumn{4}{|c|}{ Histopathological grading } \\
\hline $\mathrm{G} 1,2$ & 31 & 116 & $<0.001$ \\
\hline G3 & 25 & 29 & \\
\hline \multicolumn{4}{|c|}{ Lymphatic invasion } \\
\hline Absence & 18 & 61 & 0.196 \\
\hline Presence & 38 & 84 & \\
\hline \multicolumn{4}{|c|}{ Venous invasion } \\
\hline Absence & 10 & 38 & 0.213 \\
\hline Presence & 46 & 107 & \\
\hline \multicolumn{4}{|l|}{$\mathrm{N}$ category } \\
\hline No & 13 & 46 & 0.235 \\
\hline $\mathrm{N} 1,2$ & 43 & 99 & \\
\hline \multicolumn{4}{|l|}{ M category } \\
\hline M0 & 22 & 68 & 0.331 \\
\hline M1 & 34 & 77 & \\
\hline
\end{tabular}

drive the inherent resistance of RCRCs to anti-EGFR therapy.

Primary tumor sidedness of CRC has prognostic importance and relates to response to targeted therapy [15-18]. Recent meta-analyses reported that RCRC was a negative prognostic variable independent of TumorNode-Metastasis (TNM) stage [16]. Furthermore, patients with $R A S$ wild-type LCRC had significantly greater survival benefit from anti-EGFR therapy compared with anti-vascular endothelial growth factor (VEGF) therapy; and, conversely, RCRC had poor benefit from standard therapies including anti-EGFR therapy, but was associated with longer survival with anti-VEGF therapy $[17,18]$.
The National Comprehensive Cancer Network (NCCN) guidelines noted that cetuximab and panitumumab confer little, if any, benefit to patients with metastatic CRC if the primary tumor originated on the right side, and primary tumor sidedness is a surrogate for the non-random distribution of molecular subtypes [18]. However, the molecular background of RCRC and LCRC has not been fully elucidated, and it is still unclear why anti-EGFR therapy is less efficacious in patients with RCRC compared with patients with LCRC. Hence, we investigated genomic differences between RCRC and LCRC using CGS, focusing on identifying the mechanism driving the observed difference in response to anti-EGFR therapy. 
Table 2: Primary tumor sidedness and pathological and genetic characteristics related with deficiency of mismatch repair genes $(\mathrm{N}=\mathbf{2 0 1})$

\begin{tabular}{|c|c|c|c|}
\hline \multirow[b]{2}{*}{ Variable } & \multicolumn{2}{|c|}{ Primary tumor sidedness } & \multirow[b]{2}{*}{$P$-value } \\
\hline & Right $(n=56)$ & Left $(n=145)$ & \\
\hline \multicolumn{4}{|l|}{ Medullary type } \\
\hline Yes & 52 & 144 & 0.022 \\
\hline No & 4 & 1 & \\
\hline \multicolumn{4}{|l|}{ Mucinous type } \\
\hline Yes & 47 & 139 & 0.007 \\
\hline No & 9 & 6 & \\
\hline \multicolumn{4}{|l|}{ Signet ring type } \\
\hline Yes & 55 & 143 & 0.999 \\
\hline No & 1 & 2 & \\
\hline \multicolumn{4}{|c|}{ Tumor infiltrating lymphocytes ${ }^{\mathrm{a}}$} \\
\hline Yes & 13 & 23 & 0.223 \\
\hline No & 43 & 122 & \\
\hline \multicolumn{4}{|l|}{ MLH1/MSH2 status } \\
\hline Normal & 22 & 69 & 0.013 \\
\hline Abnormal & 10 & 9 & \\
\hline \multicolumn{4}{|c|}{ Hypermutated phenotype } \\
\hline Hypermutated & 10 & 7 & 0.008 \\
\hline Non-hypermutated & 46 & 138 & \\
\hline
\end{tabular}

${ }^{\text {a }}$ Cut-off value $=10$ lymphocytes $/ 5$ high power fields.

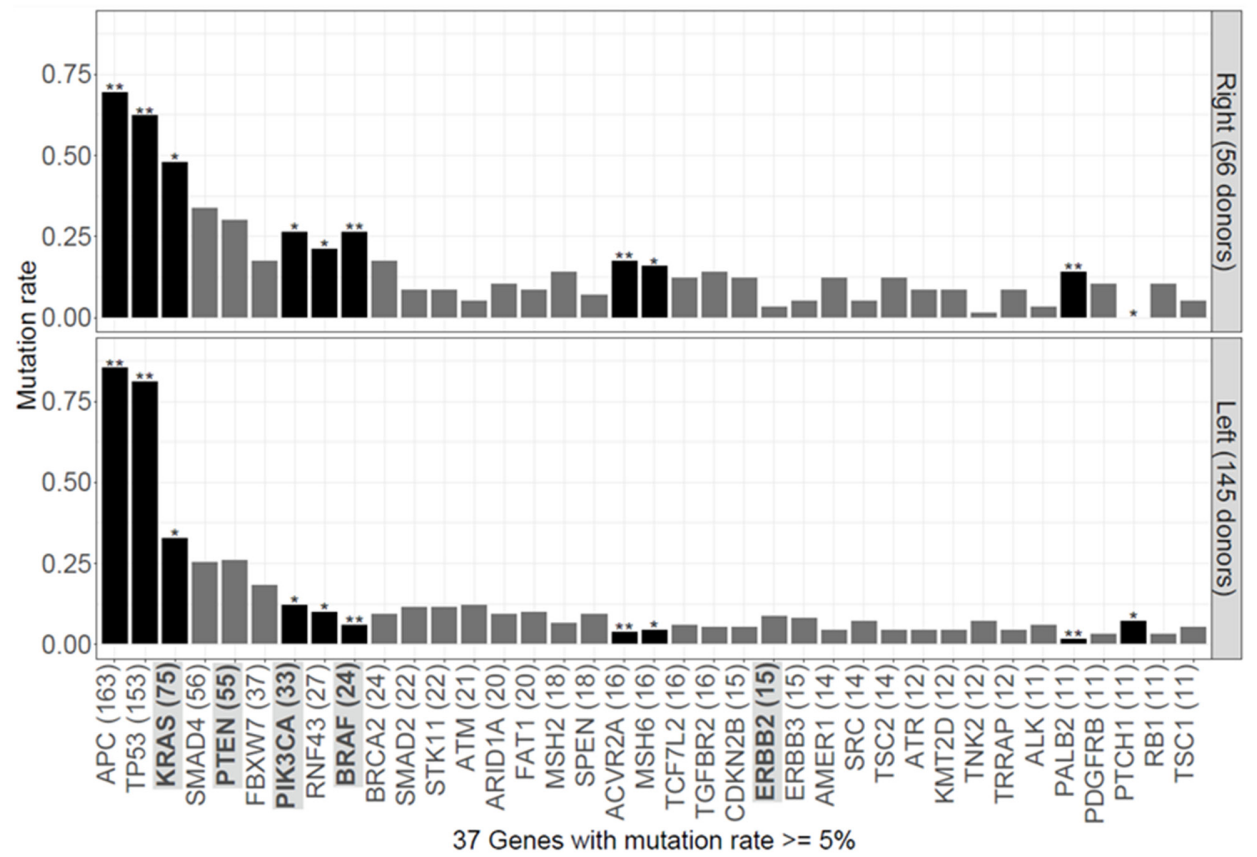

Figure 2: Distribution of genetic alterations in right-sided and left-sided colorectal cancer. Dark bars indicate genes with a significant difference $(P<0.05$, two-tailed Fisher's exact test or Chi-squared test) in the frequency of genetic alterations compared with other-sided donors. Light bars indicate genes that are not significantly different $\left({ }^{*}, P<0.05 ;{ }^{* *}, P<0.01\right)$. The genes associated with antiEGFR resistance were highlighted. 
CGS has been shown to detect numerous genetic alterations, including driver mutations, in many solid cancers $[24,25]$. Mutations in the RAS pathway, such as $K R A S$, $N R A S$, and $B R A F$, are benchmarks to determine treatment strategies for patients with metastatic CRC. The NCCN guidelines state that all patients with metastatic CRC should have tumor tissue genotyped for $K R A S, N R A S$, and $B R A F$ mutations, and patients with any known KRAS or NRAS mutation should not be treated with anti-EGFR therapy such as cetuximab and panitumumab [18]. In the present analysis, we assumed that genetic alterations in TK receptors, the RAS pathway, or the PI3K pathway are possible mechanisms underlying resistance to anti-EGFR therapy [22, 23]. We successfully detected genetic alterations, not only in the RAS pathway, but also among TK receptors and the PI3K pathway that may be associated with resistance to anti-EGFR therapy. Furthermore, patients with RCRC showed a significantly worse PFS than those with LCRC.

Cancer genome profiling seeks to enable precision medicine, modifying therapies based on the unique genomic changes inherent in the individual tumor of each patient. In the present analysis, we showed an association between tumor sidedness and gene mutations, which may explain the difference in efficacy of anti-EGFR therapy in RCRC compared with LCRC. The genomic background of RCRC as revealed by CGS is consistent with the results of previous meta-analyses [15-17] and the NCCN guidelines regarding the relevance of tumor sidedness [18]. However, we also demonstrated that approximately $10 \%$ of RCRC patients had the "all wild-type" phenotype with no mutations detected in TK receptors or the RAS or PI3K pathways, and therefore, theoretically, these patients would be considered as responders to anti-EGFR therapy despite having RCRC. As such, while we showed that RCRC commonly demonstrates a genomic profile associated with resistance to anti-EGFR therapy, we propose future analyses should focus on individual tumors rather than primary tumor sidedness to best facilitate precision medicine.

CGS has ability to detect numerous actionable mutations that can guide new treatment strategies. In this analysis, a novel finding was PALB2 mutations occurring significantly more frequent in RCRC than LCRC. PALB2 is a DNA maintenance gene, where the encoded protein binds to and colocalizes with BRCA2 in nuclear foci, and plays a role of tumor suppression [27]. In CRC, the significance of $P A L B 2$ mutations has not been elucidated, and this is the first report regarding $P A L B 2$ mutations in relation to $\mathrm{CRC}$ sidedness. PALB2 mutations are considered to be actionable,

\section{TK receptor / RAS pathway / PIK3CA pathway alterations in Stage I-IV patients}

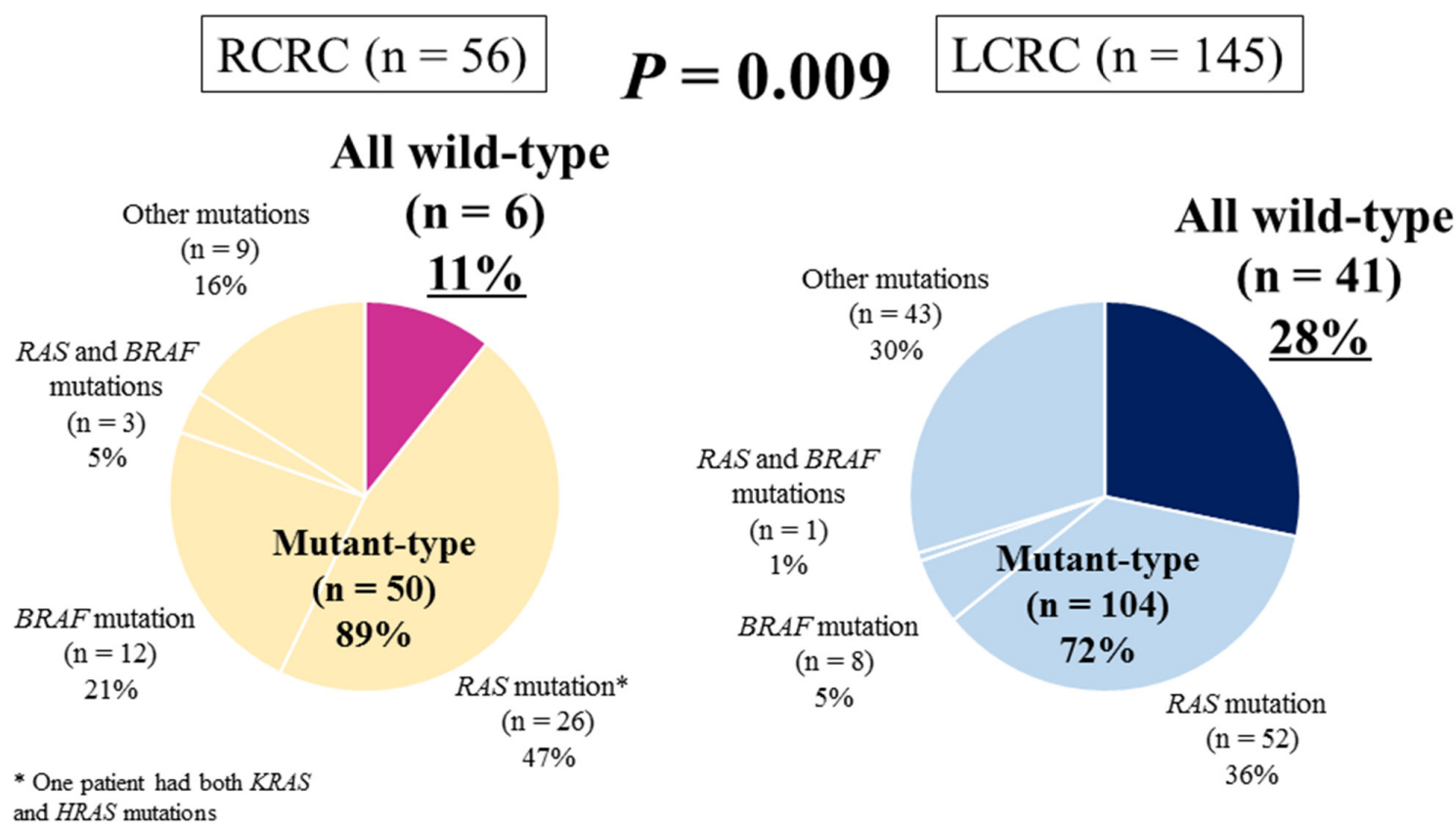

Figure 3: Percentage of genetic alterations associated with resistance to anti-EGFR therapy in right-sided colorectal cancer and left-sided colorectal cancer. Genetic alterations in TK receptors (ERBB2, MET, EGFR, FGFR1, and PDGFRA), RAS pathway (KRAS, NRAS, HRAS, BRAF, and MAPK2K1), and PI3K pathway (PTEN and PIK3CA) were evaluated using comprehensive genomic sequencing of the 415-gene panel. Patients who had no alterations in all 12 genes were defined as "all wild-type". RCRC, rightsided colorectal cancer; LCRC, left-sided colorectal cancer. 
Table 3: Association between primary tumor sidedness and gene alterations of TK receptors/RAS pathway/PI3K pathway $(\mathrm{N}=\mathbf{2 0 1})$

\begin{tabular}{|c|c|c|c|}
\hline \multirow[b]{2}{*}{ Variable } & \multicolumn{2}{|c|}{ Primary tumor sidedness } & \multirow{2}{*}{$P$-value } \\
\hline & Right $(n=56)$ & Left $(n=145)$ & \\
\hline \multicolumn{4}{|l|}{$E R B B 2$ status } \\
\hline Wild-type & 54 & 132 & 0.243 \\
\hline Mutant $^{\mathrm{a}}$ & 2 & 13 & \\
\hline \multicolumn{4}{|l|}{$M E T$ status } \\
\hline Wild-type & 55 & 139 & 0.676 \\
\hline Mutant $^{\mathrm{a}}$ & 1 & 6 & \\
\hline \multicolumn{4}{|l|}{$E G F R$ status } \\
\hline Wild-type & 56 & 141 & 0.578 \\
\hline Mutant & 0 & 4 & \\
\hline \multicolumn{4}{|l|}{ FGFR1 status } \\
\hline Wild-type & 56 & 135 & 0.065 \\
\hline Mutant & 0 & 10 & \\
\hline \multicolumn{4}{|c|}{ PDGFRA status } \\
\hline Wild-type & 55 & 144 & 0.481 \\
\hline Mutant ${ }^{\mathrm{a}}$ & 1 & 1 & \\
\hline \multicolumn{4}{|l|}{$K R A S$ status } \\
\hline Wild-type & 29 & 97 & 0.047 \\
\hline Mutant & 27 & 48 & \\
\hline \multicolumn{4}{|l|}{$N R A S$ status } \\
\hline Wild-type & 54 & 142 & 0.620 \\
\hline Mutant & 2 & 3 & \\
\hline \multicolumn{4}{|l|}{$H R A S$ status } \\
\hline Wild-type & 55 & 143 & 0.999 \\
\hline Mutant & 1 & 2 & \\
\hline \multicolumn{4}{|l|}{$B R A F$ status } \\
\hline Wild-type & 41 & 136 & $<0.001$ \\
\hline Mutant & 15 & 9 & \\
\hline \multicolumn{4}{|c|}{$M A P K 2 K 1$ status } \\
\hline Wild-type & 54 & 137 & 0.729 \\
\hline Mutant & 2 & 8 & \\
\hline \multicolumn{4}{|l|}{ PTEN status } \\
\hline Wild-type & 39 & 107 & 0.554 \\
\hline Mutant $^{b}$ & 17 & 38 & \\
\hline \multicolumn{4}{|c|}{$P I K 3 C A$ status } \\
\hline Wild-type & 41 & 127 & 0.014 \\
\hline Mutant & 15 & 18 & \\
\hline
\end{tabular}

(Continued) 


\begin{tabular}{lccc}
\hline & \multicolumn{2}{c}{ Primary tumor sidedness } & \\
\cline { 2 - 3 } Variable & Right $(\mathbf{n}=\mathbf{5 6})$ & Left $(\mathbf{n}=\mathbf{1 4 5})$ & \\
\hline Alterations in TK receptors/RAS & & & \\
pathway/PI3K pathway & 6 & 41 & 0.024 \\
0 & 24 & 56 & \\
1 & 26 & 48 & 0.009 \\
2 or more & 6 & 41 & \\
All wild-type & 50 & 104 & \\
Mutant-type & & & \\
\hline
\end{tabular}

${ }^{\text {a }}$ Including mutation and amplification.

${ }^{\mathrm{b}}$ Including mutation and deletion

and are a biomarker for response to Poly (ADP-ribose) polymerase (PARP) inhibitors in pancreatic (ClinicalTrials. gov Identifier: NCT03140670) and prostatic (ClinicalTrials. gov Identifier: NCT02952534) cancers. In this analysis, we found 8 of 56 (14\%) RCRCs had PALB2 mutations compared with 3 of 145 (2\%) LCRCs. Thus, targeting PALB2 may represent a future treatment strategy for RCRC.
To the best of our knowledge, this is the first report describing a genomic overview of RCRC and LCRC using CGS. However, this analysis has several limitations. First, it was a retrospective analysis performed at two institutions and included a relatively small number of patients. Second, the selection of genomic biomarkers of resistance outside of $R A S$ is not yet well supported by prospective studies. Third,
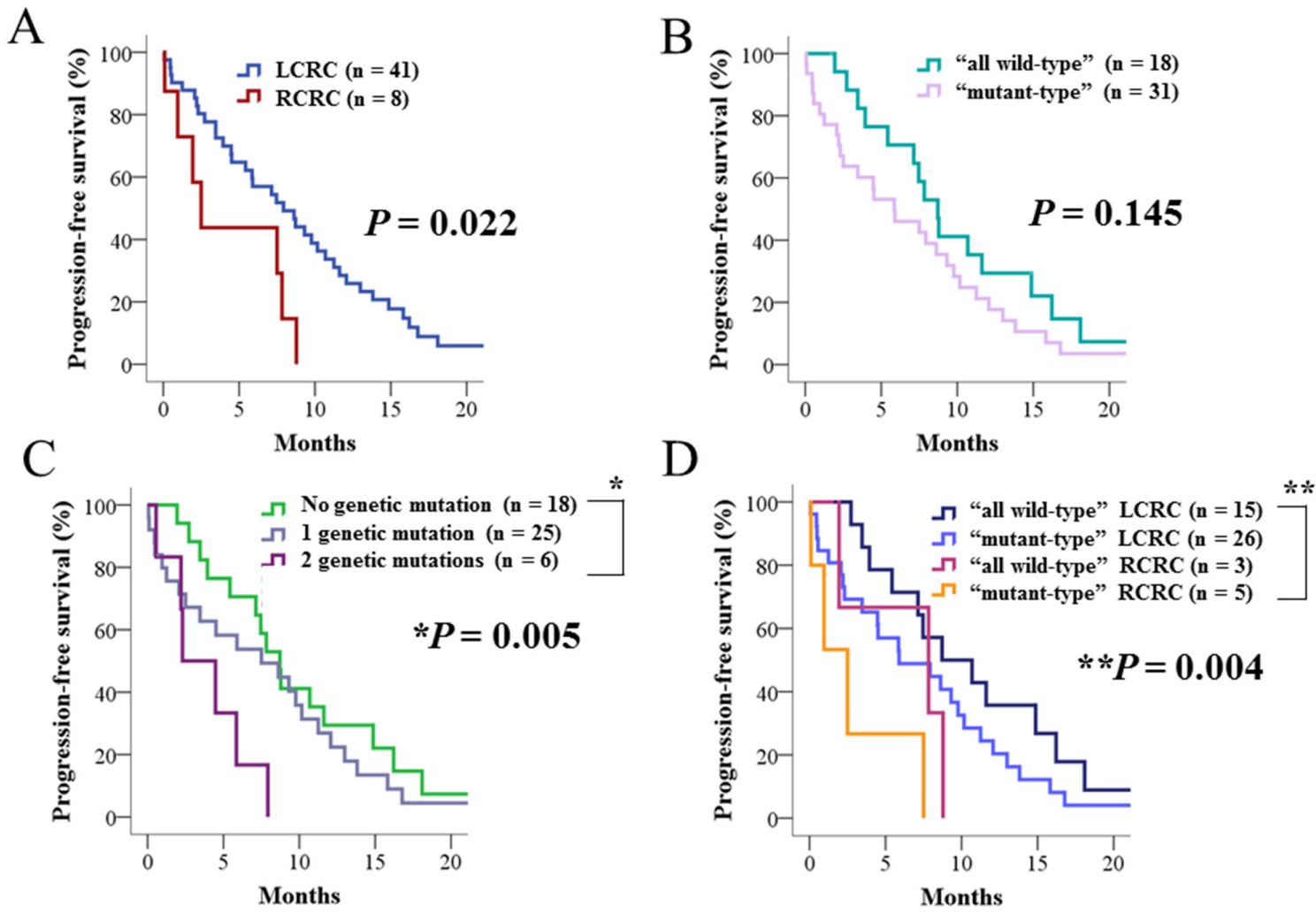

Figure 4: Progression-free survival of patients who received anti-EGFR therapy in addition to cytotoxic chemotherapy. (A) Progression-free survival stratified by primary tumor sidedness. (B) Progression-free survival stratified by genetic alterations associated with resistance to anti-EGFR therapy. (C) Progression-free survival stratified by the number of genetic alterations associated with resistance to anti-EGFR therapy. (D) Progression-free survival stratified by primary tumor sidedness and genetic alterations. "All wild-type" indicates patients without any genetic alterations associated with resistance to anti-EGFR therapy, and "mutant-type" indicates those with one or more genetic alterations. RCRC, right-sided colorectal cancer; LCRC, left-sided colorectal cancer. 
Table 4: Association between primary tumor sidedness and clinicopathological characteristics in 49 patients with anti-EGFR therapy in addition to cytotoxic chemotherapy

\begin{tabular}{|c|c|c|c|}
\hline \multirow[b]{2}{*}{ Variable } & \multicolumn{2}{|c|}{ Primary tumor sidedness } & \multirow{2}{*}{$P$-value } \\
\hline & Right $(n=8)$ & Left $(n=41)$ & \\
\hline \multicolumn{4}{|l|}{ Age (years) } \\
\hline$<65$ & 4 & 27 & 0.443 \\
\hline$\geq 65$ & 4 & 14 & \\
\hline \multicolumn{4}{|l|}{ Sex } \\
\hline Male & 4 & 27 & 0.443 \\
\hline Female & 4 & 14 & \\
\hline \multicolumn{4}{|c|}{ Tumor size (mm) } \\
\hline$<50$ & 5 & 19 & 0.463 \\
\hline$\geq 50$ & 3 & 22 & \\
\hline \multicolumn{4}{|l|}{ T category } \\
\hline $\mathrm{T} 2,3$ & 4 & 18 & 0.999 \\
\hline $\mathrm{T} 4$ & 4 & 23 & \\
\hline \multicolumn{4}{|c|}{ Histopathological grading } \\
\hline $\mathrm{G} 1,2$ & 3 & 32 & 0.033 \\
\hline G3 & 5 & 9 & \\
\hline \multicolumn{4}{|c|}{ Lymphatic invasion } \\
\hline Absence & 1 & 14 & 0.406 \\
\hline Presence & 7 & 27 & \\
\hline \multicolumn{4}{|c|}{ Venous invasion } \\
\hline Absence & 2 & 6 & 0.601 \\
\hline Presence & 6 & 35 & \\
\hline \multicolumn{4}{|l|}{$\mathrm{N}$ category } \\
\hline No & 1 & 5 & 0.999 \\
\hline $\mathrm{N} 1,2$ & 7 & 36 & \\
\hline \multicolumn{4}{|l|}{ M category } \\
\hline M0 & 1 & 1 & 0.421 \\
\hline M1a & 4 & 23 & \\
\hline M1b & 3 & 17 & \\
\hline \multicolumn{4}{|l|}{$K R A S$ status } \\
\hline Wild-type & 7 & 39 & 0.421 \\
\hline Mutant & 1 & 2 & \\
\hline \multicolumn{4}{|l|}{$B R A F$ status } \\
\hline Wild-type & 5 & 38 & 0.047 \\
\hline Mutant & 3 & 3 & \\
\hline
\end{tabular}




\begin{tabular}{|c|c|c|c|}
\hline \multirow[b]{2}{*}{ Variable } & \multicolumn{2}{|c|}{ Primary tumor sidedness } & \multirow{2}{*}{$P$-value } \\
\hline & Right $(\mathrm{n}=8)$ & Left $(n=41)$ & \\
\hline \multicolumn{4}{|c|}{$\begin{array}{l}\text { Alterations in TK receptors/RAS pathway/PI3K } \\
\text { pathway excluding } K R A S \text { and } B R A F \text { mutations }\end{array}$} \\
\hline Absence & 7 & 20 & 0.059 \\
\hline Presence & 1 & 21 & \\
\hline \multicolumn{4}{|c|}{$\begin{array}{l}\text { Alterations in TK receptors/RAS pathway/PI3K } \\
\text { pathway }\end{array}$} \\
\hline 0 & 3 & 15 & 0.492 \\
\hline 1 & 5 & 20 & \\
\hline 2 & 0 & 6 & \\
\hline All wild-type & 3 & 15 & 0.999 \\
\hline Mutant-type & 5 & 26 & \\
\hline \multicolumn{4}{|l|}{ Anti-EGFR drug } \\
\hline Cetuximab & 2 & 9 & 0.999 \\
\hline Panitumumab & 6 & 32 & \\
\hline \multicolumn{4}{|l|}{ Anti-EGFR therapy } \\
\hline Initial therapy & 3 & 9 & 0.386 \\
\hline Subsequent therapy & 5 & 32 & \\
\hline \multicolumn{4}{|c|}{ Chemotherapy added to anti-EGFR therapy } \\
\hline Oxaliplatin-based & 3 & 7 & 0.195 \\
\hline Irinotecan-based & 3 & 29 & \\
\hline Anti-EGFR drug only & 2 & 5 & \\
\hline
\end{tabular}

as patients who received anti-EGFR therapy were analyzed retrospectively, we could not definitively associate primary tumor sidedness with response to anti-EGFR therapy. Fourth, as the number of RCRC patients who received anti-EGFR therapy was small, we need for increasing the number of RCRC patients in future. However, we did demonstrate that RCRC was significantly associated with genetic alterations associated with resistance to anti-EGFR therapy, which provides a plausible mechanism of resistance to anti-EGFR therapy in patients with RCRC.

In conclusion, we show RCRC is more likely to harbor genetic alterations associated with resistance to anti-EGFR therapy compared with LCRC, and primary tumor sidedness is a surrogate for a non-random distribution of genetic alterations in CRC.

\section{MATERIALS AND METHODS}

\section{Patients}

This retrospective analysis was performed in accordance with the Helsinki Declaration and the protocol was approved by the Ethics Committee of the
School of Medicine, Niigata University. We randomly selected and enrolled 201 patients diagnosed with stage I - IV CRC based on the $7^{\text {th }}$ edition of the American Joint Committee on Cancer staging manual [28] who had a primary tumor resection between 2009 and 2015 at Niigata University Medical and Dental Hospital or Niigata Cancer Center Hospital. In this analysis, we included the 201 independent individuals, all unrelated, confirmed from our database and medical charts. Patients with familial adenomatous polyposis or inflammatory bowel disease were excluded.

\section{Primary tumor sidedness and clinicopathological characteristics}

Primary tumor location was determined by operative findings. Cancer in the cecum, ascending colon, hepatic flexure, or transverse colon was classified as right-sided; and cancer in the splenic flexure, descending colon, sigmoid colon, rectosigmoid, or rectum was classified as left-sided $[29,30]$. Histopathological features associated with RCRC, such as medullary type, mucinous type, signet ring type, and tumor-infiltrating lymphocytes 
were analyzed by a previously reported method [31]. MutL homologue 1 (MLH1)/MutS homologue 2 (MSH2) status was evaluated in 110 of the 201 patients by immunohistochemistry with anti-MLH1 (1:50; BD Biosciences PharMingen, San Diego, CA) and anti-MSH2 (1:50; Leica Microbiosystems, Tokyo, Japan) antibodies. Hypermutation was defined as a tumor with MSI-H and/ or high tumor mutation burden (TMB), as described previously [25], using CGS. TMB was calculated as the number of non-synonymous mutations per megabase of sequence in the panel (panel size $=1.3 \mathrm{Mb}$ ). To be classified as hypermutated, the threshold of TMB was set as the lowest TMB observed in tumors with MSI-H. Tumors with mutations in POLE or other DNA repair genes can have very high TMB but not show MSI-H [25].

\section{CGS analysis of primary tumors}

Archival tissue in the form of formalin-fixed, paraffin-embedded (FFPE) tumor or unstained tissue sections obtained during primary tumor resection were used for CGS. An independent pathologist evaluated tumor content in each sample using hematoxylin and eosin-stained slides to ensure $>50 \%$ tumor content was present. Where applicable, unstained slides were macrodissected to enrich for tumor content and DNA was extracted using a BioStic FFPE Tissue DNA Isolation Kit (Mo Bio Laboratories, Inc., Carlsbad, CA). All sample preparation, CGS, and analytics were performed in a CLIA/CAP-accredited laboratory (KEW Inc., Cambridge, MA). DNA fragment (50-150 ng) libraries were prepared and enriched for the CancerPlex 415-gene panel (KEW Inc.) $[25,26]$, a large clinically validated panel of 415 genes enriched for coding regions and selected introns of known cancer-related genes. Sequencing was performed on Illumina MiSeq and NextSeq platforms with an average $500 \times$ sequencing depth. Genomic data were then processed through a proprietary bioinformatics platform and knowledgebase to identify multiple classes of genomic abnormalities including single nucleotide substitutions, small insertions/deletions, copy number variations, and translocations. Single nucleotide variant (SNV) and insertion or deletion (indel) calling were only performed in genomic regions intended to be captured by the assay (region of interest). We set a standard threshold of $10 \%$ allelic fraction for calling SNVs and indels to focus on primary truncal driver mutations and avoid subclonal events. Copy number variants were called for exons as well as globally. We segmented regions using a Fused-Lasso method and export the results to a VCF file. The threshold for gain was $>2.5$ fold and for loss was $<0.5$ fold. Variants were filtered or flagged according to technical quality (e.g. coverage, allelic fraction, number of supporting reads), presence in previously characterized normal samples, or presence/absence in the following databases: dbSNP, ExAC, COSMIC, ClinVar, and KEW.
SNVs and indels in VCF format were annotated using SnpEff and the output was adapted according to HGVS recommendations $[25,26]$.

\section{Genetic alterations in TK receptors and the RAS and PI3K pathways in RCRC and LCRC}

Genetic alterations of TK receptors (ERBB2, MET, EGFR, FGFR1, and PDGFRA), RAS pathway (KRAS, $N R A S, H R A S, B R A F$, and MAPK2K1), and PI3K pathway (PTEN and PIK3CA) were analyzed using CGS of the 415gene panel. We defined patients who had no alterations in all 12 genes as "all wild-type"; theoretically, these patients should respond to anti-EGFR therapy $[22,23]$. We defined the remaining patients with genetic alterations as "mutanttype". We also estimated the incidence of "all wild-type" for RCRC and LCRC. In this analysis of 201 patients, 49 received anti-EGFR therapy. In these 49 patients, we investigated the efficacy of anti-EGFR therapy according to primary tumor sidedness and genetic alterations associated with resistance to anti-EGFR therapy.

\section{Statistical analysis}

Statistical analyses were performed with IBM SPSS Statistics 22 (IBM Japan, Inc., Tokyo, Japan). A Fisher's exact test or Chi-squared test was used to evaluate associations between primary tumor sidedness and clinicopathological characteristics, and primary tumor sidedness and genetic alterations were evaluated with CGS. The association between primary tumor sidedness and genetic alterations associated with resistance to antiEGFR therapy was examined by Fisher's exact test or Chi-squared test. PFS rates in patients treated with antiEGFR therapy (cetuximab or panitumumab) in addition to cytotoxic chemotherapy were estimated using KaplanMeier analysis. A log-rank test was used to assess for a significant difference between right-sided and left-sided tumors. $P$-values $<0.05$ were considered statistically significant.

\section{Author contributions}

Yoshifumi Shimada: Study conception, acquisition of data, analysis and interpretation of data, and drafting of manuscript. Hitoshi Kameyama: Acquisition and interpretation of data. Masayuki Nagahashi: Acquisition and interpretation of data. Hiroshi Ichikawa: Acquisition and interpretation of data. Yusuke Muneoka: Acquisition and interpretation of data. Ryoma Yagi: Acquisition and interpretation of data. Yosuke Tajima: Acquisition and interpretation of data. Takuma Okamura: Acquisition and interpretation of data. Masato Nakano: Acquisition and interpretation of data. Jun Sakata: Acquisition and interpretation of data. Takashi Kobayashi: Acquisition and interpretation 
of data. Hitoshi Nogami: Acquisition of data and critical revision of manuscript. Satoshi Maruyama: Acquisition of data and critical revision of manuscript. Yasumasa Takii: Acquisition of data and critical revision of manuscript. Tetsu Hayashida: Interpretation of data and critical revision of manuscript. Hiromasa Takaishi: Interpretation of data and critical revision of manuscript. Yuko Kitagawa: Interpretation of data and critical revision of manuscript. Eiji Oki: Interpretation of data and critical revision of manuscript. Tsuyoshi Konishi: Interpretation of data and critical revision of manuscript. Fumio Ishida: Interpretation of data and critical revision of manuscript. Shin-ei Kudo: Interpretation of data and critical revision of manuscript. Jennifer E. Ring: Acquisition of data and critical revision of manuscript. Alexei Protopopov: Acquisition of data and critical revision of manuscript. Stephen Lyle: Acquisition of data and critical revision of manuscript. Yiwei Ling: Analysis of data and critical revision of manuscript. Shujiro Okuda: Analysis of data and critical revision of manuscript. Takashi Ishikawa: Analysis of data and critical revision of manuscript. Kohei Akazawa: Analysis of data and critical revision of manuscript. Kazuaki Takabe: Interpretation of data and critical revision of manuscript. Toshifumi Wakai: Study conception, acquisition of data, analysis and interpretation of data, critical revision of manuscript. All authors read and approved the final manuscript.

\section{CONFLICTS OF INTEREST}

Jennifer E. Ring, Alexei Protopopov, and Stephen Lyle are employees of KEW Inc., who have been granted stock options by KEW Inc. The remaining authors declare that they have no competing interests.

\section{FUNDING}

This project was supported by Denka Co., Ltd. Tokyo, Japan and in part by JSPS KAKENHI Grant Number JP15K10130.

\section{REFERENCES}

1. Loupakis F, Yang D, Yau L, Feng S, Cremolini C, Zhang W, Maus MK, Antoniotti C, Langer C, Scherer SJ, Müller T, Hurwitz HI, Saltz L, et al. Primary tumor location as a prognostic factor in metastatic colorectal cancer. J Natl Cancer Inst. 2015; 107.

2. Weiss JM, Pfau PR, O'Connor ES, King J, LoConte N, Kennedy G, Smith MA. Mortality by stage for rightversus left-sided colon cancer: analysis of surveillance, epidemiology, and end results--Medicare data. J Clin Oncol. 2011; 29: 4401-4409.
3. Ishihara S, Watanabe T, Akahane T, Shimada R, Horiuchi A, Shibuya H, Hayama T, Yamada H, Nozawa K, Matsuda $\mathrm{K}$, Maeda K, Sugihara K. Tumor location is a prognostic factor in poorly differentiated adenocarcinoma, mucinous adenocarcinoma, and signet-ring cell carcinoma of the colon. Int J Colorectal Dis. 2012; 27: 371-379.

4. Lee MS, McGuffey EJ, Morris JS, Manyam G, Baladandayuthapani V, Wei W, Morris VK, Overman MJ, Maru DM, Jiang ZQ, Hamilton SR, Kopetz S. Association of $\mathrm{CpG}$ island methylator phenotype and EREG/AREG methylation and expression in colorectal cancer. $\mathrm{Br} \mathrm{J}$ Cancer. 2016; 114: 1352-1361.

5. Powell AG, Wallace R, McKee RF, Anderson JH, Going JJ, Edwards J, Horgan PG. The relationship between tumour site, clinicopathological characteristics and cancer-specific survival in patients undergoing surgery for colorectal cancer. Colorectal Dis. 2012; 14: 1493-1499.

6. Takahashi Y, Sugai T, Habano W, Ishida K, Eizuka M, Otsuka K, Sasaki A, Takayuki Matsumoto, Morikawa T, Unno M, Suzuki H. Molecular differences in the microsatellite stable phenotype between left-sided and right-sided colorectal cancer. Int J Cancer. 2016; 139: 2493-2501.

7. Tran B, Kopetz S, Tie J, Gibbs P, Jiang ZQ, Lieu CH, Agarwal A, Maru DM, Sieber O, Desai J. Impact of BRAF mutation and microsatellite instability on the pattern of metastatic spread and prognosis in metastatic colorectal cancer. Cancer. 2011; 117: 4623-4632.

8. Iacopetta B. Are there two sides to colorectal cancer? Int J Cancer. 2002; 101: 403-408.

9. Hutchins G, Southward K, Handley K, Magill L, Beaumont C, Stahlschmidt J, Richman S, Chambers P, Seymour M, Kerr D, Gray R, Quirke P. Value of mismatch repair, KRAS, and BRAF mutations in predicting recurrence and benefits from chemotherapy in colorectal cancer. J Clin Oncol. 2011; 29: 1261-1270.

10. Shen H, Yang J, Huang Q, Jiang MJ, Tan YN, Fu JF, Zhu LZ, Fang XF, Yuan Y. Different treatment strategies and molecular features between right-sided and left-sided colon cancers. World J Gastroenterol. 2015; 21: 6470-6478.

11. Breivik J, Lothe RA, Meling GI, Rognum TO, BørresenDale AL, Gaudernack G. Different genetic pathways to proximal and distal colorectal cancer influenced by sexrelated factors. Int J Cancer. 1997; 74: 664-669.

12. Van Cutsem E, Köhne CH, Hitre E, Zaluski J, Chang Chien CR, Makhson A, D'Haens G, Pintér T, Lim R, Bodoky G, Roh JK, Folprecht G, Ruff P, et al. Cetuximab and chemotherapy as initial treatment for metastatic colorectal cancer. N Engl J Med. 2009; 360: 1408-1417.

13. Douillard JY, Siena S, Cassidy J, Tabernero J, Burkes R, Barugel M, Humblet Y, Bodoky G, Cunningham D, Jassem J, Rivera F, Kocákova I, Ruff P, et al. Randomized, phase III trial of panitumumab with infusional fluorouracil, leucovorin, and oxaliplatin (FOLFOX4) versus FOLFOX4 alone as first-line treatment in patients with previously 
untreated metastatic colorectal cancer: the PRIME study. J Clin Oncol. 2010; 28: 4697-4705.

14. Douillard JY, Oliner KS, Siena S, Tabernero J, Burkes R, Barugel M, Humblet Y, Bodoky G, Cunningham D, Jassem J, Rivera F, Kocákova I, Ruff P, et al. PanitumumabFOLFOX4 treatment and RAS mutations in colorectal cancer. N Engl J Med. 2013; 369: 1023-1034.

15. Holch JW, Ricard I, Stintzing S, Modest DP, Heinemann V. The relevance of primary tumour location in patients with metastatic colorectal cancer: A meta-analysis of first-line clinical trials. Eur J Cancer. 2017; 70: 87-98.

16. Petrelli F, Tomasello G, Borgonovo K, Ghidini M, Turati L, Dallera P, Passalacqua R, Sgroi G, Barni S. Prognostic Survival Associated With Left-Sided vs Right-Sided Colon Cancer: A Systematic Review and Meta-analysis. JAMA Oncol. 2016 Oct 27. https://doi.org/10.1001/ jamaoncol.2016.4227. [Epub ahead of print].

17. Tejpar S, Stintzing S, Ciardiello F, Tabernero J, Van Cutsem E, Beier F, Esser R, Lenz HJ, Heinemann V. Prognostic and Predictive Relevance of Primary Tumor Location in Patients With RAS Wild-Type Metastatic Colorectal Cancer: Retrospective Analyses of the CRYSTAL and FIRE-3 Trials. JAMA Oncol. 2016 Oct 10. https://doi.org/10.1001/ jamaoncol.2016.3797. [Epub ahead of print].

18. National Comprehensive Cancer Network. NCCN clinical practice guidelines in oncology-rectal cancer (version 2. 2017). Available: https://www.ncen.org/professionals/ physician_gls/pdf/colon.pdf [accessed April 3, 2017].

19. Van Cutsem E, Cervantes A, Adam R, Sobrero A, Van Krieken JH, Aderka D, Aranda Aguilar E, Bardelli A, Benson A, Bodoky G, Ciardiello F, D'Hoore A, Diaz-Rubio $\mathrm{E}$, et al. ESMO consensus guidelines for the management of patients with metastatic colorectal cancer. Ann Oncol. 2016; 27: 1386-1422.

20. Cunningham D, Humblet Y, Siena S, Khayat D, Bleiberg H, Santoro A, Bets D, Mueser M, Harstrick A, Verslype C, Chau I, Van Cutsem E. Cetuximab monotherapy and cetuximab plus irinotecan in irinotecan-refractory metastatic colorectal cancer. N Engl J Med. 2004; 351: 337-345.

21. Saltz LB, Meropol NJ, Loehrer PJ Sr, Needle MN, Kopit J, Mayer RJ. Phase II trial of cetuximab in patients with refractory colorectal cancer that expresses the epidermal growth factor receptor. J Clin Oncol. 2004; 22: 1201-1208.

22. Bertotti A, Papp E, Jones S, Adleff V, Anagnostou V, Lupo B, Sausen M, Phallen J, Hruban CA, Tokheim C, Niknafs
N, Nesselbush M, Lytle K, et al. The genomic landscape of response to EGFR blockade in colorectal cancer. Nature. 2015; 526: 263-267.

23. Bertotti A, Migliardi G, Galimi F, Sassi F, Torti D, Isella C, Corà D, Di Nicolantonio F, Buscarino M, Petti C, Ribero D, Russolillo N, Muratore A, et al. A molecularly annotated platform of patient-derived xenografts ("xenopatients") identifies HER2 as an effective therapeutic target in cetuximab-resistant colorectal cancer. Cancer Discov. 2011; 1: 508-523.

24. Cancer Genome Atlas Network. Comprehensive molecular characterization of human colon and rectal cancer. Nature. 2012; 487: 330-337.

25. Nagahashi M, Wakai T, Shimada Y, Ichikawa H, Kameyama H, Kobayashi T, Sakata J, Yagi R, Sato N, Kitagawa Y, Uetake H, Yoshida K, Oki E, et al. Genomic landscape of colorectal cancer in Japan: clinical implications of comprehensive genomic sequencing for precision medicine. Genome Med. 2016; 8:136. https://doi.org/10.1186/ s13073-016-0387-8.

26. Shimada Y, Yagi R, Kameyama H, Nagahashi M, Ichikawa H, Tajima Y, Okamura T, Nakano M, Nakano M, Sato Y, Matsuzawa T, Sakata J, Kobayashi T, et al. Utility of comprehensive genomic sequencing for detecting HER2-positive colorectal cancer. Hum Pathol. 2017 Feb 21. https://doi.org/10.1016/10.1016/j.humpath.2017.02.004. [Epub ahead of print].

27. Waddell N, Pajic M, Patch AM, Chang DK, Kassahn KS, Bailey P, Johns AL, Miller D, Nones K, Quek K, Quinn MC, Robertson AJ, Fadlullah MZ, et al. Whole genomes redefine the mutational landscape of pancreatic cancer. Nature. 2015; 518: 495-501.

28. Edge SB, Byrd DR, Compton CC, Fritz AG, Greene FL, Trotti A, eds. AJCC Cancer Staging Manual. 7th edition: Springer, New York, 2010.

29. Lee GH, Malietzis G, Askari A, Bernardo D, Al-Hassi HO, Clark SK. Is right-sided colon cancer different to left-sided colorectal cancer? - a systematic review. Eur J Surg Oncol. 2015; 41: 300-308.

30. Li FY, Lai MD. Colorectal cancer, one entity or three. J Zhejiang Univ Sci B. 2009; 10: 219-229.

31. Bosman FT, Carneiro F, Hruban RH, Theise ND, eds. WHO Classification of Tumours of the Digestive System. 4th edition; IARC, Lyon, 2010. 